\title{
CEM ANOS DO DIREITO INTERNACIONAL PÚBLICO (1913) DE JOSÉ MENDES (1861-1918) - OLHAR REFLEXIVO SOBRE O DIREITO INTERNACIONAL NAS ARCADAS (1911-1918)
}

100 YEARS OF PUBLICATION OF ‘DIREITO INTERNACIONAL PUBLICO’ (1913) BY JOSÉ MENDES (1861-1918) INTERNATIONAL LAW AT THE SÃO PAULO UNIVERSITY LAW SCHOOL AT ARCADAS

Paulo Borba Casella*

Resumo:

Ensino do Direito Internacional nas Arcadas - José Mendes foi professor ordinário da disciplina (1911-1918) - sua obra Direito internacional público - preleções (1913) completa cem anos de publicação.

Palavras-chave: José Mendes. Direito Internacional Público.

\begin{abstract}
:
Teaching International Law at the "Arcadas", the Law School of the University of São Paulo - José Mendes was full professor for this chair (1911-1918) - his book on Lectures of Public International Law, Direito internacional público - preleções (1913) now completes one hundred years of publication.
\end{abstract}

Keywords: José Mendes. International Public Law.

Introdução

De 1911 até 1918, quando foi assassinado em Mococa, com um tiro, regeu a Cadeira de Direito Internacional público e privado, o dr. José Mendes. Em 1913 o então "professor ordinário da Faculdade de Direito de São Paulo", publicou a sua obra "Direito internacional público: preleções. São Paulo: Duprat \& Comp.”. A obra de Mendes (1913) é exemplo de produção brasileira de Direito Internacional, anterior à primeira guerra mundial. Esta merece ser lembrada, nesta edição da Revista da Faculdade de Direito, que ora completa 120 anos, desde o primeiro volume, de 1893, e se propõe fazer olhar retrospectivo sobre a escola e o ensino das diferentes áreas do direito nesta desenvolvido.

Na presente edição comemorativa dos 120 anos da Revista, se faz homenagem às mais de quatro décadas de trabalho, competente e dedicado, desempenhado pelo editor e alma de nossa Revista, Antonio Augusto Machado de Campos Neto, bacharel em Direito e jornalista. Ao mesmo tempo, grande passo foi dado este ano na divulgação do acervo respeitável de doze décadas: nossa revista passa a ser publicada simultaneamente em versão impressa e eletronicamente (on line) e o inteiro acervo desta - digitalizado - passa

\footnotetext{
Professor Titular de Direito Internacional Público e Vice-Diretor da Faculdade de Direito da Universidade de São Paulo.
} 
a estar também disponível eletronicamente, para alcance de público consideravelmente mais amplo, no Brasil e no Exterior. Honrar a tradição significa a manter viva e renovada.

Depois desta introdução, o presente artigo se ordena no exame da obra de Mendes (1913), considerando brevemente: sucessão de homens e obras (i); contexto histórico (ii); a obra de José Mendes (iii) e conclusão (iv).

\section{Sucessão de homens e obras}

José Mendes se inscreve na tradição da Casa, na qual o Direito Internacional está presente desde o primeiro momento, nas Arcadas. Estas nasceram sob a égide do "Direito das Gentes". Isso desde a aula inaugural de José Maria Avelar Brotero, em março de 1828 - o primeiro professor de Direito, nomeado por D. Pedro I, no Brasil, foi um professor de Direito Internacional. E a primeira aula inaugural na casa foi ministrada por esse docente, que regeu a cátedra de "Direito Eclesiástico, Diplomático e das Gentes", como a Cadeira então se denominava, por mais de quatro décadas. Inaugurava-se assim, desde o nascimento, a forte tradição de Direito Internacional nas Arcadas. Que se manteve sempre presente e desde então nunca foi interrompida. ${ }^{1}$

Neste mesmo ano, se completam também 150 anos da publicação da segunda edição das Questões sobre presas marítimas, de José Maria Avelar Brotero, originalmente editada em 1836, ${ }^{2}$ em São Paulo; em segunda edição, em 1863. ${ }^{3}$ Do primeiro lente de Direito das Gentes entre nós, que teve longeva carreira - regeu a cátedra por mais de quatro décadas - este seria o seu último livro.

CASELLA, P. B. Direito internacional nas Arcadas: a aula inaugural de 16 de fevereiro de 2009. Revista da Faculdade de Direito da Universidade de São Paulo, São Paulo, v. 104, p. 931-966, 2009.

2 Questões sobre presas marítimas, "oferecidas ao cidadão Rafael Tobias de Aguiar, pelo autor J. M. A. BROTERO" (São Paulo: Typographia de Costa Silveira, 1836) declara-se "atento venerador" de Tobias de AGUIAR e faz-lhe dedicatória: "Com a proteção de V. Exa. me animo a fazer publicar uma pequena obra com o título - Questões sobre presas marítimas - fruto de algum trabalho, e que julgo servirá para dar algumas idéias àqueles que tem de julgar e defender objetos tão interessantes. / A benevolência de V.E. relevará a falta de estilo, e os erros da doutrina; doutrina assaz espinhosa e bem pouco conhecida entre nós. Não tendo eu ao meu alcance senão os meus próprios livros, heide por força cair em omissões." (...) Exemplar da Biblioteca da FDUSP.

3 BROTERO, José Maria de Avellar. Questões sobre presas marítimas. 2. ed. aum. São Paulo: Typographia - imparcial - de J. R. de Azevedo Marques, 1863), registrava no prólogo: "Conheço que este meu trabalho é imperfeito, e muito sinto que nesta segunda edição ficasse com tantos erros, resta-me a esperança que os homens competentes hão de ter indulgência com tais defeitos, e só censurar a doutrina e nesta parte peçolhes severidade, pois pedir considerações seria ter em pouco a ciência e o meu dever. / Este livro não é uma obra de teorias ou doutrinas especulativas; é um compêndio de fatos e princípios do Direito Marítimo admitido pelas nações civilizadas. / Da primeira edição suprimi tudo quanto me pareceu fora da matéria, aumentei porém muita doutrina que faltava. / Cito os escritores, de que tenho notícia, que publicaram suas obras depois da minha primeira edição - 1836. / Nesta segunda edição procurei ser útil aos meus Escolares, no estudo do Direito das Gentes, e não olhei, nem me lembrei, que o meu trabalho pudesse ser estimado pela elegância e pureza de linguagem". Exemplar da Biblioteca da FDUSP. 
As trajetórias pessoais destes dois mestres, Brotero e Mendes compõem etapas da dimensão mais ampla e mais duradoura: o plano institucional do Direito Internacional nas Arcadas. Existe belo conjunto a ser resgatado, nessa trajetória de mais de 180 anos de ensino ininterrupto de Direito Internacional nesta Casa, sob a regência dos homens que conduziram tal Cadeira, ao mesmo tempo em que se delineiam os grandes temas, nestes quase dois séculos: do Direito das Gentes, ao Direito Internacional clássico à percepção deste no contexto pós-moderno, inclusive com diálogo com as fontes.

Ao mesmo tempo em que mudanças recentes mostram a novidade e a especificidade do "estado da arte" no Direito Internacional, sob o impacto direto dos fatos, com ênfase em algumas características deste enquanto sistema institucional e normativo internacional - a internacionalidade como dado inerente e essencial do estudo e do ensino da disciplina - não é possível deixar de olhar mais adiante do que cada um pode alcançar fazer. É preciso ter em mente esse dado institucional, para que as coisas façam sentido, situar o olhar em plano mais amplo, desde o passado aos presentes, neste tempo e no encadeamento entre os tempos. Por isso se considera brevemente o contexto histórico.

\section{Contexto histórico}

Percebe-se a diversidade das situações históricas e das tendências da prática, marcada pela diversidade de soluções, mas estas não devem impedir a determinação de linhas gerais da evolução do Direito Internacional, ${ }^{4}$ o que se reflete na diversidade de tratamento da matéria, pela doutrina. A linha geral será no sentido de apontar as grandes linhas da condução do ensino do direito internacional, na tradição da nossa escola. Tratase de situar o Direito Internacional no conjunto da formação jurídica, onde se mostre a permanência de conceitos e dos princípios.

A história da Escola de Direito de São Paulo se imbrica, se mescla, se liga à história do País, e de modo assinalado, quantas das questões aqui suscitadas tiveram e tem impacto sobre o que em âmbito nacional se enfrentaria - já foi, muitas vezes, dito, e ouvir-se-á outras vezes - e isto se dá não somente no passado. ${ }^{5}$

$4 \quad$ Remeto à linha mestra do trabalho desenvolvido no Direito Internacional: CASELLA, P. B. Fundamentos do direito internacional pós-moderno. São Paulo: Quartier Latin, 2008; CASELLA, P. B. Direito internacional dos espaços. São Paulo: Atlas, 2009; CASELLA, P. B. Direito internacional no tempo antigo. São Paulo: Atlas, 2012; CASELLA, P. B. Direito internacional no tempo medieval e moderno até Vitoria. São Paulo: Atlas, 2012; CASELLA, P. B. Direito internacional no tempo moderno de Suarez a Grócio. São Paulo: Atlas, 2013; ao lado da atualização nas sucessivas edições de Accioly - Nascimento e Silva - CASELLA, P. B. Manual de direito internacional público. 21. ed. São Paulo: Saraiva, 2014); NASCIMENTO E SILVA CASELLA - BITTENCOURT NETO, Direito internacional diplomático. , 4. ed. São Paulo: Saraiva, 2012.

5 Como assinalava na aula inaugural de 2009, a criação de cursos superiores quando se instaura um país, como se deu no então recém-instaurado império brasileiro, não negligenciou o papel destes, para a formação não somente de quadros de gestão - como se desejava e se declara desde o início, e evitar que se mantivesse a 
Como assinalava em 2009, na aula inaugural "Direito Internacional nas Arcadas", as situações serão necessariamente diferentes, mas não será por isso que as normas terão de ser totalmente distintas, não será preciso reinventar a roda a cada geração, mas não se pode deixar de ver quando muda e quanto mudou o mundo nestas gerações, desde a instauração da veneranda cátedra de direito eclesiástico, diplomático e das gentes, tal como enceta o magistério Avelar Brotero, ${ }^{6}$ de 1828 até aposentar-se este em 1871, e desde então. Mais uma vez, cumpre assinalar, a matéria conta marco relevante: o ensino do direito internacional se põe desde o primeiro momento entre nós - assinalado pela aula inaugural do curso da Faculdade de Direito de São Paulo, em março de 1828. Esse dado confere categoria de legitimidade histórica ao direito internacional nesta casa: justamente se mantém e se renova, ao longo das décadas, até o momento presente - e quanto muda e se renova o direito internacional, ao mesmo tempo em que se inscreve no conjunto do ensino jurídico, nesta Casa e neste País.

Da pesquisa nos anuários da Faculdade de Direito, de 1891 até $1969,{ }^{7}$ extraise a seguinte evolução do ensinamento do Direito Internacional na nossa Casa: Jesuíno Ubaldo Cardoso de Mello, em 1891 e 1892, rege a primeira Cadeira da segunda série do curso de Ciências Sociais, "Direito das Gentes, diplomacia e história dos tratados". Não há registro para 1893.

Em 1894 o programa de ensino de "Direito das gentes, diplomacia e história dos tratados" foi apresentado pelo "lente cathedratico", Dr. Américo Brasiliense de Almeida Mello. Em 1895, 1896 e 1898, o programa de ensino de "Direito internacional público e diplomacia" foi apresentado pelo "lente cathedratico", Dr. Alfredo Lima. Não há registro para o ano de 1897 .

Nos anos de 1899 e 1900, o programa de "Direito internacional público e diplomacia" foi apresentado pelo "lente substituto", Dr. José Mariano Corrêa de Camargo Aranha. Este docente, em 1901, passa a ser "lente cathedratico" e o programa, por vez primeira, menciona "Direito internacional público e privado e diplomacia". De 1902 até

subordinação intelectual - e mais do que isso, em relação à célula-mãe, a Faculdade de Direito de Coimbra. Também se exprime essa criação como dado de formação e de afirmação de identidade nacional, que então se esboçava.

6 REALE, Miguel. Avellar Brotero, ou a ideologia sob as Arcadas. São Paulo: Saraiva, 1956. (Publicado originalmente em 1955, In: Horizontes do direito e da história: estudos de filosofia do direito e da cultura). p. 195-224, depois publicado em (Filosofia em São Paulo. edição 1962. São Paulo: Grijalbo/ EDUSP, 2. ed. rev. e reestruturada, 1976, p. 63-91).

7 Conforme apontava na aula inaugural de 2009, Direito internacional nas Arcadas, com base na pesquisa nos “Anuários da Faculdade de Direito (1891 a 1969)", como sempre, proficientemente desenvolvido pela equipe da Biblioteca da Faculdade de Direito da Universidade de São Paulo. A toda a equipe fica, aqui, mais uma vez, consignado, o meu agradecimento. 
1911, com a mesma denominação "Direito internacional público e privado e diplomacia”, o programa é apresentado pelo "lente substituto”, Dr. José Bonifácio de Oliveira Coutinho. A seguir, o professor de Direito Internacional da nossa Casa foi José Mendes (1861-1918). Nascido no interior de Minas Gerais, a 27 de março de 1861. Diplomou-se pela Escola Normal de Campanha, dedicando-se ao magistério secundário. Mais tarde transferiu-se para São Paulo, matriculando-se na Faculdade de Direito, bacharelando-se em 1891. Passou, então, a advogar no interior paulista (Mococa). Em 1911 ingressou no corpo docente da Faculdade, onde chegou a catedrático e teria a oportunidade de reger Cadeira na Casa. ${ }^{8}$ Foi membro fundador do Instituto dos Advogados de São Paulo.

Por decreto de 3 de novembro de 1911, José Mendes (1861-1918) foi nomeado professor ordinário da Cadeira de Direito Internacional Público e Privado, da qual tomou posse em 11 do mesmo mês. ${ }^{9}$ Exerce a titularidade da Cátedra, até ser assassinado em Mococa, no interior de São Paulo, em 1918, aos 57 anos. ${ }^{10}$

O sucessor de José Mendes será Theophilo Benedicto de Souza Carvalho, ${ }^{11}$ oito anos mais novo, nomeado professor catedrático de Direito Internacional Público e Privado, por decreto de 29 de maio de 1918, da qual tomou posse em 10 de junho seguinte.

A partir de 1918, como reflexo das mudanças e da evolução ocorridas, pela primeira vez, o ensinamento de Direito Internacional, na Faculdade de Direito de São Paulo passará a dividir-se entre: Direito Internacional Público, $1^{\mathrm{a}}$ cadeira do $2^{\circ}$ ano, “apresentado pelo professor cathedratico Dr. José Mendes e adotado para o ano de 1918 pelo professor doutor Theophilo B. de Souza Carvalho", enquanto o "programa de ensino

8 CDPB - Centro de documentação do pensamento brasileiro (Org.). Dicionário bio-bibliográfico de autores brasileiros. Salvador: CDPB / Brasília: Senado Federal, 1999. p. 317-318; curiosamente registra teria José Mendes ocupado a cadeira de "filosofia do Direito". Embora tivesse publicado os seus (MENDES, José. Ensaios de philosophia do direito. São Paulo: Duprat, 1905. 2. v.); José Mendes regeu a cadeira de Direito Internacional Público e Privado, não a de Filosofia do Direito, como equivocadamente registra a referida publicação.

9 FERREIRA, Waldemar. A Congregação da Faculdade de Direito de São Paulo na centúria de 1827 a 1927. Revista da Faculdade de Direito de São Paulo, São Paulo, separata. São Paulo: Typographia Siqueira, 1928 p. 109-110).

10 Sobre o autor veja-se: COSTA, José da Silva. Carta do eminente jurisconsulto. In: Ensaios de philosophia do direito. São Paulo: Duprat, 1905; VAMPRÉ, Spencer. Memórias para a história da Academia de São Paulo. 2. ed. Brasília: INL, 1977. p. 427-429); CDPB: Centro de Documentação do Pensamento Brasileiro (Org.). Dicionário bio-bibliográfico de autores brasileiros. Salvador: CBPB / Brasília: Senado Federal, 1999. p. 317-318; onde se assinala que a bibliografia de José Mendes inclui, ainda: (MENDES, José. Servidões de caminho. São Paulo, s/d); além de seus já referidos ( . Ensaios de philosophia do direito. São Paulo: Duprat, 1905) e ( . Direito internacional público, 1913).

11 W. FERREIRA (op. cit., 1928. p. 116): "Inscreveu-se em vários concursos abertos na Faculdade de Direito de São Paulo, em 1897, em 1902, em 1909, em 1910 e 1911. Disputou a livre-docência em 1911 e a obteve em 28 de outubro de 1914 com o Dr. Manoel Aureliano de Gusmão. Neste mesmo ano, por decreto de 20 de outubro, foi nomeado professor extraordinário efetivo da primeira seção. Tomou posse em 28 do mesmo mês, recebendo o grau de doutor." 
de Direito Internacional Privado, $5^{\mathrm{a}}$ cadeira do $5^{\circ}$ ano", foi igualmente apresentado pelo mesmo catedrático, Dr. José Mendes, ${ }^{12}$ e continuado por Souza Carvalho.

Assim se construiu a sucessão dos docentes (ordinários, catedráticos e titulares da cadeira de Direito Internacional), a partir de seu primeiro titular, Avelar BROTERO até José Mendes. Entre a aula inaugural de Brotero, marco efetivo da fundação da escola, até o término da primeira guerra mundial foram exatos 90 anos de exercício docente em Direito Internacional nas Arcadas.

Esses dados foram lembrados para a seguir situar as vertentes centrais da obra.

3. A obra de José Mendes

"Da interpenetração orgânica desses períodos e de sua ressonância no Direito das Gentes se dava conta [naquela altura] há mais de seis décadas, no decorrer da primeira guerra mundial, em página ainda repassada de atualidade, José Mendes, que o prelecionava na Faculdade de São Paulo". ${ }^{13}$

Aqui há dado que merece ser destacado, na oportuna a percepção da evolução histórica do direito, pondera Vicente Marotta Rangel:14 "Teria a análise do direito das gentes contemporâneo o efeito de prescindir da busca desse direito em tempos menos recentes? A leitura dos ensaios componentes da obra autorizará a resposta negativa e nos faz reconhecer neles a presença dos ensinamentos de José Mendes. O contemporâneo surge aí como resumo e complemento das fases anteriores, a que os ensaios recorrem toda vez que se faça necessário compreender e vistoriar os quadrantes e o cerne do direito perquirido". ${ }^{15}$

12 A Souza Carvalho caberá dar prosseguimento ao ensino do direito internacional privado até 1938. Nesse mesmo ano, consta menção ao "programa do Prof. Dr. Theophilo B. de Souza Carvalho, adotado pelo Prof. Dr. Antonio de Sampaio Dória".

13 RANGEL, V. Marotta. Introdução aos princípios do direito internacional contemporâneo de A. A. Cançado Trindade. In: TRINDADE, Antonio Augusto Cançado. Princípios do direito internacional contemporâneo. Brasília: Ed. UnB, 1981. p. v-xiv, cit. p. vii) considera o "próprio Direito Internacional cujas origens remontam, pelo menos em sua feição moderna, à época da descoberta do novo mundo, mas cujas estruturas e lineamentos sofrem o influxo das transformações sociais, a influência do progresso tecnológico e científico, o vigoroso condicionamento dos fatores políticos, econômicos, culturais. Trata-se, pois, a rigor do international law, segundo a terminologia dos países de common law, do qual se exclui necessariamente o direito internacional privado, conflict of laws." O que se põe "na perspectiva dos momentos decisivos da sociedade global de que todos participamos como membros, mais espectadores que protagonistas."

14 RANGEL, V. Marotta. Pref. cit., 1980, p. viii; v. tb. RANGEL, V. Marotta. Public international law: the last five decades. In: DOLINGER, Jacob; ROSENN, Keith. (ed.). A panorama of Brazilian law. Miami / Rio de Janeiro: Univ. of Miami North-South Center / Ed. Esplanada, 1992. p. 287-308, esp. p. 308.

15 RANGEL, V. Marotta. Pref. cit., 1980, loc. cit.). 
Durante os anos de sua docência jurídica, José Mendes publicou não somente sobre temas de Direito Internacional como de Direito Civil e de Filosofia do Direito, com destaque para as obras: Ensaios de philosophia do direito. São Paulo: Duprat \& Cia., 1905. 2 v.; Das servidões de caminho: Direito romano e pátrio. São Paulo: Duprat \& Cia., 1906; antes do Direito internacional público: preleções. São Paulo: Duprat \& Cia., 1913. ${ }^{16}$ Dentre as suas publicações contam-se, ainda numerosos artigos. ${ }^{17}$

Ao tratar o assunto, segundo perspectiva histórica, inserem-se os anos em que José Mendes regeu a Cadeira (1911-1918), as Preleções de direito internacional público se inscrevem no período que precede e durante o qual acontece a primeira guerra mundial. Que traria grandes transformações ao sistema institucional e ao Direito Internacional. A morte, que o ceifou em 1918, não deixou a José Mendes tempo para refletir na sua obra as transformações decorrentes dessa mutação de fase histórica.

Na época, em que Mendes leciona na casa, desenvolvimentos consideráveis começam a se esboçar, no Direito Internacional, com as conferências de paz da Haia, de 1899 e 1907 e as convenções daí resultantes. Até 1907, quando se reuniu, na Haia, o concílio dos povos cultos, apenas foi possível tentar a regulamentação da guerra, para que fosse menos cruel, e menos destruidora das criações materiais e morais, a que a humanidade mais fortemente se afeiçoa, como comentava Clóvis Bevilaqua (1920). ${ }^{18}$ Aliás Beviláqua, grande jurista e marcante personalidade da primeira metade do século passado, é presença constante na obra de José Mendes: este se reporta frequentemente a Clóvis Bevilaqua. Ao formular a sua definição de Direito Internacional, ao lado de internacionalistas como Phillimore e Walker, Mendes (1913) também mencionava Pedro Lessa como "autorizado mestre" do Direito. ${ }^{19}$

Para compreender o contemporâneo é preciso entender o que veio antes e poder conferir coerência ao conjunto, mediante a compreensão do que precede, para se chegar ao ora existente e daí para o que poderá vir a seguir. Destacar um momento fará perder a compreensão do todo.

16 FERREIRA, W. op. cit., 1928, loc. cit.; menciona, inadvertidamente, 1915 como data da publicação: Direito internacional público: preleções do Dr. José Mendes "Professor ordinário da Faculdade de Direito de São Paulo".

17 José MENDES, ... ; ... ; ... ; ... ; José MENDES, Relação entre o direito internacional público e o direito nacional nos paises americanos (18 RT 81 (1918)).

18 BEVILAQUA, Clóvis. Prólogo. In: PEREIRA. M. F. Pinto. Soberania das nações. São Paulo: C. Teixeira \& Cia., 1920, p. ix-xii: "em 1919, realisou-se um grande progresso ethico-jurídico. A codificação levada a effeito não mais teve por objecto as leis da guerra, porém os princípios tendentes a comatel-a e reduzil-a. Agora, sim começaram os homens a legislar sobre a paz, a preparar as condições sociaes e jurídicas da paz. Antes não puderam senão legislar sobre a guerra".

19 MENDES, J. Direito internacional público. cit., 1913, cap. I, "these I - definição do Direito Internacional Público", p. 9-18. 
“O direito está para o organismo social, como a veste para o organismo individual: um e outro acompanham o desenvolvimento do respectivo corpo. Cada fase da evolução social contém a fase anterior, com alguma coisa a mais. Cada fase é o resumo das fases anteriores, numa e noutra evolução", retomaria J. Mendes em artigo publicado na RT (1918). ${ }^{20}$

José Mendes (1913), ${ }^{21}$ apontava com discernimento o papel a ser desempenhado pelo Direito Internacional: "este ramo da árvore jurídica em formação, adaptado à sociedade internacional, civitas maxima, societas societatum, ora também em formação e cujas condições de vida e desenvolvimento exigem, como as da sociedade nacional, reconhecimento e garantias tendentes à manutenção do equilíbrio das espheras de actividade dos estados, unidades do organismo social mundial". ${ }^{22}$

A obra de Mendes (1913) contendo o "programma de Direito Internacional Público" "23 se organiza em cinco capítulos e trinta "teses". O amplo capítulo I embora tenha o singelo título de "introdução" - conta oito "teses". ${ }^{24}$ desde a definição do Direito Internacional Público, ${ }^{25}$ fundamentos do Direito Internacional Público; ${ }^{26}$ posição enciclopédica do Direito Internacional Público, ${ }^{27}$ gênese e evolução do Direito Internacional Público; ${ }^{28}$ objeções contra a existência do Direito Internacional Público; ${ }^{29}$

20 MENDES, José. Relação entre o direito internacional público e o direito nacional nos países americanos. (18 RT 81 (1918)).

21 MENDES, José. Direito internacional público: prelecções. São Paulo: Duprat \& Comp., 1913, 'prefácio', datado de 15 de novembro de 1913: "Este livro reflecte em synthese as minhas prelecções de Direito Internacional Público, na Faculdade de Direito de São Paulo. / Transumpto da explicação de todas as theses de meu programma, traz a nomenclatura de todas as questões de mais destaque no assumpto, discutidas e resolvidas durante o curso. / Contém as linhas essenciaes dos institutos jurídico-mundiaes, sem descer a detalhes, consoante já aconselhavam os Estatutos da Universidade de Coimbra de 1772. / A linguagem é simples, conforme o salutar exemplo dos modernos expositores da matéria scientífica. Sciencia e rhetorica são coisas que se não attraem. ornari res ipsa vetat, contenta doceri."

22 Mendes, J. (op. cit., 1913, 'prefácio’ cit.) encerrava-o: “É, pois, um manual de estudantes. Escrevel-o custoume grande somma de exforços, a que me não poupei, cônscio do intento de satisfazer a uma necessidade vivamente sentida e repetidamente manifestada por meus discípulos, a cujas mãos o entrego, certo de que farão delle um dos factores do progresso de nossa cultura jurídico-internacional."

23 MENDES, José. Programma de direito internacional público. $1^{\circ}$ período (s/d, s/ editora, prefácio datado de 15 de novembro de 1913) tem conteúdo exatamente igual ao do livro "Direito internacional público preleções" (op. cit., 1913) excetuada a página de rosto, com este título. Pode-se presumir teriam um e outro cumprido funções distintas, no sentido de serem as Preleções o 'manual' de ensino da disciplina, enquanto o Programma teria como finalidade o registro do conteúdo da matéria lecionada.

24 MENDES, J. op. cit., 1913, cap. I - introdução, p. 9-122.

25 MENDES, J. op. cit., 1913, “these I", § 1-4, p. 9-18).

26 MENDES, J. op. cit., 1913, “these II”, § 5-7, p. 19-27).

27 MENDES, J. op. cit., 1913, “these III”, § 8-10, p. 28-35).

28 MENDES, J. op. cit., 1913, “these IV”, § 11-14, p. 36-51).

29 MENDES, J. op. cit., 1913, "these V”, § 15-19, p. 52-63). 
relações do Direito Internacional Público com outras ciências; ${ }^{30}$ fontes do Direito Internacional Público; ${ }^{31}$ até a codificação do Direito Internacional Público. ${ }^{32}$

Ao definir a matéria, Mendes propunha: "direito internacional público é o conjunto orgânico das condições de vida e desenvolvimento do estado e da sociedade dos estados, dependentes da vontade humana, e garantidas, ou que o devem ser, pela força coercitiva do poder público". ${ }^{33}$ E acrescentava: "direito internacional público é o conjunto sistemático dos princípios e normas reguladoras das relações jurídicas dos estados entre si e com a sociedade internacional". 34

Formulava Mendes anseio em relação à evolução da matéria: "O ideal do direito, pois, é universalizar-se, é tornar-se mundial. E isto se realizará quando cada indivíduo puder dizer, com inteira verdade e completa exatidão, o que por previsão genial dizia Marco Aurélio: civius sum totius mundi. ${ }^{35}$ Explicava Mendes:

A existência do direito internacional público é, pois, uma indução inelutável dos fatos observados por toda a parte e em todas as épocas, revelando universalmente e sempre a natureza do homem e dos diversos agrupamentos por ele formados. ${ }^{36}$

A resposta aos objetores era dada de maneira clara: "em suma: quem negar a existência do Direito Internacional não poderá afirmar a existência do Direito nacional. São duas realidades positivas necessariamente coexistentes". 37

MENDES, J. op. cit., 1913, “these VI”, § 20-24, p. 64-91.

MENDES, J. op. cit., 1913, "these VII”, § 25-41, p. 92-110.

MENDES, J. op. cit., 1913, "these VIII", § 42-47, p. 111-122.

33 MENDES, J. op. cit., 1913, "these I", $\S 4^{\circ}$ - definição do direito internacional público, p. 13): "Esta definição põe mais em destaque o elemento positivo do direito, consistente nas Facultas Agendi, do que o elemento negativo, consistente nas Normas Agendi".

34 MENDES, J. op. cit., 1913, "these I", § $4^{\circ}$, p. 14.

35 MENDES, J. op. cit., 1913, "these IV”, § 14, cit. p. 51.

36 MENDES, J. op. cit., 1913, "these V", § 19, p. 61.

37 MENDES, J. op. cit., 1913, “these V”, § 19, n. 5, p. 63. 
Quanto ao costume, em paralelo à lição de Franz von Liszt (1913, ed. 1928), lembre-se a de Mendes (1913) ${ }^{38}$ Este último, depois de situar o costume, ${ }^{39}$ com remissão à fonte romana - "Mores sunt tacitus consensus gentium longa consuetudine inveteratus" - esclarecia em relação ao 'costume jurídico internacional': “é a observância constante de uma norma reguladora das relações internacionais, que se não baseia em tratado". O costume, assim, na lição de Mendes (1913) se compõe de dois elementos: “o elemento externo é o uso, a observância constante" e o "elemento interno é a opinio necessitatis, a convicção da necessidade sentida de constituir direito esse uso". ${ }^{40}$

O capítulo II, sobre "as pessoas do direito internacional público", inclui cinco teses:41 pessoas internacionais - onde examina, sucessivamente, as noções de sociedade, de nação e de estado, as diferenças no modo como o direito público interno e o externo consideram o estado, a noção de pessoa em geral, em relação à noção de pessoa internacional pública, a extensão de seu conceito e a compreensão deste: ${ }^{42}$ "a extensão do conceito de pessoa internacional pública será o maior ou menor número de entidades que merecem essa denominação criada pela técnica internacional, para designar os seres capazes de direitos e obrigações internacionais". Nesse sentido, de maneira consentânea com a época, "o conceito de pessoa internacional, no rigor da lógica do Direito

38 CASELLA, P. B. Contemporary trends on 'opinio juris' and the material evidence of (Gilberto Amado Memorial Lecture 2013, apresentada à Comissão das Nações Unidas para o Direito internacional, em Genebra, em 17 de julho de 2013, acessível no site ilc-cdi), notava: Just to limit review to two examples of 1913, reflecting internarional law just before the first World War: MENDES, José. Direito internacional público. São Paulo: Duprat \& Cia., 1913, these VII - fontes do Direito Internacional, § 30 - noção de costume internacional, p. 98-99): refers the classical definition from Roman Law "Mores sunt tacitus consensus gentium longa consuetudine inveteratus" and then as 'costume jurídico internacional' explains: "é a observância constante de uma norma reguladora das relações internacionais, que se não baseia em tratado". Custom according to the lesson by Mendes (1913, $\S 32$ - elementos do costume, p. 100) is composed of two elements: "the external element is the use, the constant observance" and the "internal element is the opinio necessitatis, the conviction of the necessity felt that such use is in accordance with the law" (convicção da necessidade sentida de constituir direito esse uso). On his turn, LISZT, Franz Von. Le droit international: exposé systématique ("traduction française d'après la 9e édition allemande (1913)" par Gilbert Gidel avec le concours de Léon Alcindor, avant propos de James Brown Scott, Paris: Pedone, 1928, 'introduction', $\S 2$ - les sources du droit international, p. 12-15, quoted p. 12): "Le droit international a pour fondement la conscience juridique commune des États civilisés: il existe dans la mesure où cette conscience a pris corps par une expression de la volonté juridique commune. Cette volonté juridique commune se manifeste à l'extérieur: partie au moyen de la pratique juridique, partie par l'établissement formel de règles de droit. Le droit coutumier ou non-écrit résulte de la répétition des faits envisagés comme manifestation de la conscience juridique (opinio juris sive necessitatis)." And Von Liszt explained where same was to be found (op. cit., locus cit., note 2): 'C'est à la conscience juridique commune que l'on pense comme dernière source interne du droit, lorsque l'on range inexactement parmi les sources externes du droit la nécessité (Gareis) ou la reconnaissance (Holtzendorff)'.

39 MENDES, J. op. cit., 1913, these VII - fontes do direito internacional, § 30 - noção de costume internacional, p. 98-99).

40 MENDES, J. op. cit., 1913, § 32 - elementos do costume, p. 100).

41 MENDES, J. op. cit., 1913, capítulo II, theses IX a XIV, p. 123-211).

42 MENDES, J. op. cit., 1913, “these IX”, § 48 a 55, p. 123-133). 
Internacional Público, só se estende aos estados, aos povos politicamente organizados”. E expressamente declarava: "nesse sentido genuíno ficam dele excluídos": a) o soberano de qualquer nação; b) o homem, c) o papa, d) as tribus nômades e selvagens, bem como e) quaisquer outras entidades e agrupamentos sociais despidos dos caracteres constitutivos do conceito de estado". ${ }^{43}$

O Estado era, assim, caracterizado com "os principais atributos ou caracteres ou condições" que deve reunir, "para que seja reconhecido pessoa internacional pública, isto é titular de direitos, no grêmio internacional dos estados" como os seguintes: a) que sua existência seja um fato consumado; b) que ele goze de inteira independência em suas relações com outros estados; c) enfim que o mesmo se prontifique a entrar em relações com os estados já consociados, conformando-se com as normas reguladoras das relações jurídicas da alçada do Direito Internacional Público". ${ }^{44}$

O capítulo III considera a "soberania territorial" e é composto de três teses: da soberania em relação ao território e às pessoas, do território, da aquisição e perda da soberania territorial. Dentre os modos de adquirir a soberania territorial considerava: a ocupação, a acessão, os tratados, a sucessão. Prosseguia com os "modos de perder a soberania territorial". ${ }^{45}$ E ponderava serem "os modos de adquirir o domínio no direito privado, e a soberania territorial, no Direito Internacional Público", tanto num como no outro, divididos em originários e derivados: “originários são aqueles em que não há transmissão de um proprietário a outro. O adquirente é o autor de seu próprio domínio. A coisa adquirida não tinha dono" e os "derivados são aqueles em que há transmissão de um proprietário a outro. $\mathrm{O}$ adquirente tem aqui seu autor, isto é, que o fez senhor da coisa, no proprietário anterior, que lhe transmitiu o domínio". ${ }^{46}$

O capítulo IV, por sua vez, sobre "os órgãos das relações pacíficas entre os estados", ${ }^{47}$ composto por dez teses: XVIII até XXVII examina, sucessivamente: os órgãos nacionais permanentes das relações entre os estados - dos chefes de Estado, ${ }^{48}$ do Ministério das Relações Exteriores, ${ }^{49}$ dos agentes diplomáticos, ${ }^{50}$ dos deveres e atribuições dos agentes diplomáticos, ${ }^{51}$ das imunidades e prerrogativas dos agentes

43 MENDES, J. op. cit., 1913, “these IX”, § 54, “extensão do conceito de pessoa internacional pública”, p. 131-132) ressalvava: "por circunstâncias particulares e mui ponderosas, a Santa Sé goza de personalidade internacional, tanto que mantém relações diplomáticas com os estados da Europa e da América".

44 MENDES, J. op. cit., 1913, "these IX”, § 55, "comprehensão do conceito de pessoa internacional pública", p. 132-133).

45 MENDES, J. op. cit., 1913, “these XVII”, § 131, p. 263-265).

46 MENDES, J. op. cit., 1913, “these XVII”, § 131, p. 263-264).

47 MENDES, J. op. cit., 1913, “these XVII”, § 131, p. 263).

48 MENDES, J. op. cit., 1913, “these XVIII”, § 132-137, p. 266-280).

49 MENDES, J. op. cit., 1913, "these XIX”, § 138-143, p. 281-287).

50 MENDES, J. op. cit., 1913, “these XX”, § 144-154, p. 288-308).

51 MENDES, J. op. cit., 1913, “these XXI”, § 155-156, p. 309-313). 
diplomáticos, ${ }^{52}$ dos cônsules, ${ }^{53}$ dos deveres e atribuições dos cônsules, ${ }^{54}$ das imunidades e prerrogativas dos cônsules, ${ }^{55}$ dos órgãos deliberativos internacionais, ${ }^{56} \mathrm{e}$ dos órgãos judiciários internacionais. ${ }^{57}$

Como "fim da diplomacia" Mendes propunha, com base na lição de Holtzendorff, "regular as questões jurídicas internacionais, representar os interesses dos nacionais que vivem no estrangeiro, manter a paz e harmonia entre as nações, zelar da dignidade do estado representado, numa palavra ser a medianeira da troca de sentimentos e ideias entre as nações, o aparelho da penetração mundial". ${ }^{58}$

$\mathrm{O}$ capítulo $\mathrm{V}$ é dedicado ao exame "das relações jurídicas dos estados na vida pacífica internacional", ${ }^{59}$ é composto pelas teses XXVIII a XXX, e examina, por sua vez: das relações jurídicas entre os estados em geral, ${ }^{60}$ dos tratados internacionais, ${ }^{61} \mathrm{e}$ da assistência internacional contra o crime. ${ }^{62}$ Nesta última categoria inseria a extradição, em seus vários aspectos, ${ }^{63}$ de Direito Interno e Internacional, enfatizava que o instituto "pressupõe o reconhecimento do interesse recíproco de ambos [os estados] na defesa mundial contra o crime. E implica a negação do direito de asilo". ${ }^{64}$

\section{Conclusão}

Existe acervo relevante de produção nacional em Direito Internacional a ser resgatado. Esse trabalho encontra-se em curso. De ponto de vista organizacional tornouse esta antiga cadeira todo um departamento de direito internacional, e este tem caráter único, no país, enquanto núcleo, institucionalmente organizado, de mais de uma dezena de pesquisadores e docentes, nas áreas do Direito Internacional Público, Direito Internacional Privado, Direito do Comércio Internacional e Direito Comparado. É preciso que se tenha consciência da importância desse conjunto, para que se pense e se opere como equipe, e não a mera somatória de projetos individuais paralelos, por vezes conflitantes.

\footnotetext{
52 MENDES, J. op. cit., 1913, “these XXII”, § 157-174, p. 314-329).

53 MENDES, J. op. cit., 1913, “these XXIII”, § 175-188, p. 330-344).

54 MENDES, J. op. cit., 1913, “these XXIV”, § 189-190, p. 345-351).

55 MENDES, J. op. cit., 1913, “these XXV”, § 191-200, p. 352-363).

56 MENDES, J. op. cit., 1913, “these XXVI”, § 201-208, p. 364-371).

57 MENDES, J. op. cit., 1913, “these XXVII”, § 209-213, p. 372-380).

58 MENDES, J. op. cit., 1913, “these XX”, § 144, n. 3, p. 289). Compare-se NASCIMENTO E SILVA CASELLA - BITTENCOURT NETO, Direito internacional diplomático. 4. ed. São Paulo: Saraiva, 2012.

59 MENDES, J. op. cit., 1913, “these XVII”, § 131, p. 263.

60 MENDES, J. op. cit., 1913, “these XXVIII”, § 214-221, p. 381-394.

${ }_{61}$ MENDES, J. op. cit., 1913, “these XXIX”, § 222-232, p. 395-401.

62 MENDES, J. op. cit., 1913, “these XXX”, § 233-251, p. 402-441.

63 MENDES, J. op. cit., 1913, "these XXX”, § 233-251, p. 402-441 praticamente a totalidade da tese.

${ }^{64}$ MENDES, J. op. cit., 1913, “these XXX”, § 233, p. 403.
} 
Longo foi o caminho percorrido pelo ensino do Direito Internacional em nossa escola, desde as já centenárias preleções de Mendes, em 1913, até o momento presente: o leque de matérias se ampliou e a internacionalização da vida, no contexto pósmoderno sequer precisa ser enfatizada - todos percebem isso.

Assinale-se o encadeamento que conduz à construção de escola de direito internacional, nas Arcadas, ao longo destes quase duzentos anos. E quanto mudou o mundo, nos cem anos transcorridos desde as preleções de José Mendes, em 1913. As lições a serem extraídas dessa trajetória são múltiplas e são muito ricas.

São Paulo, junho de 2013.

Publicações de José Mendes

MENDES, José. Fundamento do direito internacional publico. Revista da Faculdade de Direito, São Paulo, v. 19, p. 287-292, 1911.

MENDES, José. Objecções contra a existencia do direito internacional publico. Revista da Faculdade de Direito, São Paulo, v. 19, p. 299-306, 1911.

MENDES, José. Posição encyclopedica do direito internacional publico. Revista da Faculdade de Direito, São Paulo, v. 19, p. 293-298, 1911,

MENDES, José. Qual a situação juridica do estrangeiro, dado o rompimento das relações diplomaticas entre o Brasil e o Estado a que elle pertence? Revista dos Tribunaes, São Paulo, v. 22, p. 106, 158, 257, 1917.

MENDES, José. Qual a situação juridica do estrangeiro, dado o rompimento das relações diplomaticas entre o Brasil e o Estado a que elle pertence? Revista dos Tribunaes, São Paulo, v. 23, p. 94,1917

MENDES, José. Relação entre o direito internacional publico e o direito nacional nos paizes americanos. Revista dos Tribunaes, São Paulo, v. 24, p. 81, 1917.

MENDES, José. Relações do direito internacional publico com outrtas sciencias. Revista da Faculdade de Direito, São Paulo, v. 19, p. 307-324, 1911.

MENDES, José. Acção de deposito - Questão de penhor agrícola por procurador - Tribunal de Justiça de São Paulo - Appellação civel numero 4.991 - Capital (Razões). São Paulo: Duprat \& Comp, editores, 1907.

MENDES, José. Acçao ex-empto (Consulta e resposta ). Revista Juridica, v. 3, p. 29, 1916.

MENDES, José. Annullação de partilha - Partes interessadas - Interesse dos credores. Gazeta Juridica, São Paulo, v. 41, p. 311, 1906. 
MENDES, José. Arrematação em praça - Bemfeitorias de terceiro - De quem deve haver o respectivo valor. Revista de Direito, Rio de Janeiro, v.12, p. 59, 1909.

MENDES, José. Averbação de protesto contra alienaçao (Parecer). Revista dos Tribunaes, São Paulo, v. 22, p. 326, 1917.

MENDES, José. As camaras municipaes não podem fazer leis extinguindo obrigações que assumiram para com os particulares, com quem convencionarum - O que e feito do concurso de vontades das partes, só pelo concurso de vontades das mes- (falta verso). São Paulo: Typographia Andrade \& Mello, 1906.

MENDES, José. As Camaras Municipaes não são mais obrigadas a pagar custas nos processos criminaes em que decai a justiça publica: o artigo 307 do Codigo do Processo Criminal está revogado. O Direito, Rio de Janeiro, v. 90, p. 389, 1903.

MENDES, José. Caso de desapropriação inconstitucional. Revista Juridica, v. 2, p. 269, 1916.

MENDES, José. Citação não pessoal, isto é, feita ao procurador ou sob pregão. O Direito, Rio de Janeiro, v. 88, p. 161, 1902.

MENDES, José.; VAMPRE, Spencer; ALMEIDA, Estevam de. O commercio com os subditos e sociedades allemães (Pareceres). Revista do Supremo Tribunal, Rio de Janeiro, v. 13, p. 263, 1917.

MENDES, José. Compete acção executiva ao subrogado no direito creditorio por custas. Revista dos Tribunaes, São Paulo, v. 12, p. 201, 1914.

MENDES, José. Contestação - Prazo em caso de chamamento á autoria. Revista de Direito, Rio de Janeiro, v. 31, p. 43, 1914.

MENDES, José. Credor hypothecario. Gazeta Jurídica, São Paulo, v. 35, p. 85, 1904.

MENDES, José. Da condemnaçao condicional. Revista de Direito, Rio de Janeiro, v. 12, p. 246, 1909.

MENDES, José. Da condemnação condicional - Natureza e genese da condemnação condicional - Sua evolução - Systemas - Condições - Estensão subjectiva - Fins - Notas affins e differenciaes Effeitos - Criticas - Direito patrio. Gazeta Juridica, São Paulo, v. 50, p. 3, 1904.

MENDES, José. Da espera de 20 dias. Revista de Direito, Rio de Janeiro, v. 28, p. 29, 1913.

MENDES, José. Da espera de 20 dias. Revista Juridica, v. 2, p. 385, 191.

MENDES, José. Da espera de 20 dias - Nova e verdadeira interpretação da ord. liv. $3^{\circ}$, tit. $1^{\circ} \S 18$. Revista da Faculdade de Direito, São Paulo, v. 18, p. 145-156, 1910.

MENDES, José. Da espera de 20 dias. Nova e verdadeira interpretação da Ord. liv. $3^{\circ}$, tit. $1^{\circ} \S 18$ sem mencionar editor. São Paulo, 1915.

MENDES, José. Da extincção das servidões de caminho - Causas extinctivas das servidões de caminho - Remissão ou renuncia da servidão - Confusão - Destruição de um dos predios em relação 
de servidão - Resolução do dominio do predio serviente - Prescripção extinctiva - Direito patrio. Revista de Direito, Rio de Janeiro, v. 9, p. 22, 1908.

MENDES, José. Da generalidade do conceito do direito. Revista da Faculdade de Direito, São Paulo, v. 18, p. 81-83, 1910.

MENDES, José. Das servidões de caminho - Direito romano e patrio. São Paulo: Duprat, 1906. v. 1.

MENDES, José. Das servidões de caminho - Direito romano e pátrio. São Paulo: Duprat \& Cia., 1906.

MENDES, José. Definição do direito internacional privado. Revista da Faculdade de Direito, São Paulo, v. 19, p. 277-286, 1911.

MENDES, José. Delicto - Acçao criminal e acção civil. Gazeta Juridica, São Paulo, v. 60, p. 36, 1912.

MENDES, José. Dependerá de regulamento a execução das disposições da constituição federal. Revista dos Tribunaes, São Paulo, v. 13, p. 135, 1915.

MENDES, José. Direito da mulher casada intervir no inventario dos bens do seu sogro. Gazeta Juridica, São Paulo, v. 43, p. 228, 1907.

MENDES, José. Direito publico. Revista Juridica, v. 8, p. 66, 1917.

MENDES, José. Do curador á lide. Revista de Direito, Rio de Janeiro, v. 10, p. 32, 1908.

MENDES, José. Do precário. Revista da Faculdade de Direito, São Paulo, v. 19, p. 173-185, 1911.

MENDES, José. Ensaios de philosophia do direito. Edição do autor. São Paulo: Duprat \& Cia., 1905. $2 \mathrm{v}$.

MENDES, José. Execução hypothecaria - Bens penhorados - Como devem ser apregoados e arrematados em praça. Revista de Direito, Rio de Janeiro, v. 5, p. 292, 1907.

MENDES, José. Executivo por custas no caso de subrogação - Tribunal de Justiça de São Paulo Embargos numero 6446 - Igarapava (Sustentação). São Paulo: Casa Vanorden, 1914.

MENDES, José. Furto - Tribunal de Justiça de São Paulo - Recurso crime numero 2228 - Capital (Razões). São Paulo: Duprat \& Cia. Ed., 1907.

MENDES, José. Os herdeiros respondem pelas dividas do "de cujus", além das forças da herança? (Parecer). Gazeta Juridica, v. 62, p. 29, 1913.

MENDES, José. Heréo - Quem pode ser assim considerado - Administrador de immovel agricola Actos extranhos a administraçao. Revista de Direito, Rio de Janeiro, v. 6, p. 506, 1907.

MENDES, José. Identidade de firma social implica continuidade juridica e de responsabilidade. Revista Juridica, v. 2, p. 40, 1916. 
MENDES, José. Incidentes da arrematação (Parecer). Revista Forense, Bello Horizonte, v. 7, p. 245, 1907.

MENDES, José. Indivisibilidade da confissão. Gazeta Juridica, São Paulo, v. 37, p. 287, 1905.

MENDES, José. Inventario annullado - Bens arrematados. Gazeta Juridica, São Paulo, v. 60, p. 33, 1912.

MENDES, José. Inventario nullo - Restituição dos bens arrematados - Meio legal. Revista de Direito, Rio de Janeiro, v. 3, p. 85, 1907

MENDES, José. Mandato - Estensão dos poderes do mandato - Nullidades dos actos praticados como excesso do mandato. Gazeta Juridica, São Paulo, v. 46, p. 121, 1908.

MENDES, José. Mandato - Compra e venda - Responsabilidade do mandante e do mandatario. Gazeta Juridica, São Paulo, v. 47, p. 128, 1908.

MENDES, José. A missão do tutor é proteger o pupillo e não prejudical-o - Tribunal de Justiça de São Paulo - Embargos numero 7.680 - Mococa (Sustentação e impugnação de embargos). São Paulo: Duprat \& Cia. Ed., 1915.

MENDES, José. Não é distribuida por dependencia a acção ordinaria de que usa o autor em logar da decendial, que o réo impediu, negando sua firma na forma do regulamento numero 737, de 1850, artigo 263 - Não é aggravavel o despacho que, decla- (falta verso). São Paulo: Typographia da Casa Ecletica, 1901.

MENDES, José. Não corre o prazo para o seguimento da appellação, havendo obstaculo judicial opposto pela parte contraria - Tribunal de Justiça de S. Paulo - Embargos numero 4.881 - Rio Claro (Sustentação). São Paulo: Typographia Maré, Monti \& Cia., 1907.

MENDES, José. Natureza da organização actual da sociedade mundial. Revista do Supremo Tribunal Federal, Rio de Janeiro, v. 6, p. 95, 1916.

MENDES, José. Obrigação fidejussoria - A mulher não póde ser fiadora - Mesmo quando herdeira do fiador, a mulher não é fiadora se não assumiu a obrigação do seu antecessor - Comarca de Tatuhy - Acção ordinaria (Razões finaes). São Paulo: Typographia Andrade \& Mello, 1904.

MENDES, José. Passagem de gado de um Estado para outro - Imposto de consumo - Imposto de transito. Revista de Direito, Rio de Janeiro, v. 34, p. 268, 1914.

MENDES, José; RAO, Vicente. Póde um estrangeiro, divorciado a vinculo consoante a lei de seu paiz, contrahir novas nupcias no Brasil? Revista dos Tribunaes, São Paulo, v. 25, p. 38, 1918.

MENDES, José. Póde ser tacita, em face do art. 243 do codigo civil, a autorização do marido para a mulher commerciar? Revista dos Tribunaes, São Paulo, v. 25, p. 259, 1918.

MENDES, José. Podem as seteiras constituir servidão? Revista de Direito, Rio de Janeiro, v. 26, p. $248,1912$. 
MENDES, José. Prazo de duração das sociedades commerciaes (Parecer). Gazeta Juridica, São Paulo, v. 34, p. 102, 1904.

MENDES, José. O procurador que, excedendo o mandato, exbulha, é passivel da acção de força espoliativa - Tribunal de Justiça de São Paulo - Appellação cível numero 4617 - Capital (Razões). São Paulo: Typographia de J. P. Cardozo, 1906.

MENDES, José. O procurador que, excedendo o mandato, esbulha, é passivel da acção de força espoliativa - Tribunal de Justiça de São Paulo - Appellação cível numero 4.617 - Capital (Razões). São Paulo: Typographia de J. P. Cardozo, 1906.

MENDES, José. A pronuncia não suspende o exercício das funcções publicas. Gazeta Juridica, São Paulo, v. 44, p. 142, 1907.

MENDES, José. A pronuncia não suspende o exercicio das funcções publicas. Revista Forense, Bello Horizonte, v. 11, p. 345, 1909.

MENDES, José; MALDONADO, Renato Alvim. Quem responde pelo acto do prefeito municipal? - Facto allegado por uma parte não precisa ser provado pela outra - O prefeito municipal não é responsável pelos actos da Camara Municipal - Falta verso(vire) (Allegações). São Paulo: Duprat \& Comp., 1910.

MENDES, José. Quem tem pae casado em segundas nupcies, mas não tem filhos, e sim apenas irmãos germanos, pode deixar em testamento à sua mulher, alem de metade de seus bens, a núa propriedade dos bens constitutivos da outra metade e vindos da mãe. Revista da Faculdade de Direito de São Paulo, São Paulo, v. 18, p. 79-80, 1910.

MENDES, José. Questão de cobrança - Pretensa successão de firma - Tribunal de Justiça de São Paulo - Appellação civel numero 8.053 - Santos. São Paulo: Estabelecimento Graphico Romano \& Pereira, 1915.

MENDES, José. Questão de indemnização de madeira - Tribunal de Justiça de São Paulo - Embargos nº 4427 - Jahú (Sustentaçao dos embargos). São Paulo: Typographia Andrade \& Mello, 1906.

MENDES, José. Questão de indemnização de madeira - O condômino, que tira madeira não contida em sua quota, deve satisfazer ao condomino prejudicado - Tribunal de Justiça de São Paulo - Embargos numero 4.427 - Jahu (Sustentação). São Paulo: Typographia Andrade \& Mello, 1906.

MENDES, José. Questão de indemnização de damno "ex delicto" - Tribunal de Justiça de São Paulo - Embargos numero 4.224 - Jahu (Impugnação). São Paulo: Typographia Andrade \& Mello, 1905.

MENDES, José. Questão de injurias em depoimento de testemunhas - Tribunal de Justiça de São Paulo - Appellação crime numero 3.774 - Capital (Razões). São Paulo: Duprat \& Cia. Ed., 1906.

MENDES, José. Questões de perda de mandato de vereador - Supremo Tribunal Federal - Recurso extraordinário - Municipio de Rio Preto (Razões). São Paulo: Weiszflog Irmãos Ed., 1912. 
MENDES, José. Questão de servidão publica de caminho municipal - Tribunal de Justiça de S. Paulo - Embargos numero 8.129 - Lorena (Sustentação dos embargos). São Paulo: Casa Duprat, 1916.

MENDES, José. Recebida a appellação no effeito devolutivo sómente, deve ficar traslado no juizo "a quo" - Tribunal de Justiça de São Paulo - Aggravo numero 4489 - Capital (Memorial). São Paulo: Duprat \& Cia., 1906.

MENDES, José. Rehabilitação do fallido. Gazeta Juridica, São Paulo, v. 35, p. 14, 1904.

MENDES, José. Revogação de doação por ingratidão da donataria que injuriou gravemente os doadores - Tribunal de Justiça de São Paulo - Embargos numero 4903 - Capital (Impugnação). São Paulo: Daprat \& Comp., 1907.

MENDES, José. Sello dos recibos. Revista de Direito, Rio de Janeiro, v. 34, p. 267, 1914.

MENDES, José. Servidão de caminho. Revista da Faculdade de Direito, S ão Paulo. v. 19, p. 171$172,1931$.

MENDES, José. Servidão - Falta de registro. Revista dos Tribunaes, São Paulo, v. 13, p. 136, 1915.

MENDES, José. Só por escriptura publica póde-se provar contra a confissão de recebimento constante de escriptura publica - A prova testemunhal é a mais fallivel de todas - Tribunal de Justiça de São Paulo - Embargos numero 4.262 - Santos (Sustentação). São Paulo: Typographia Andrade \& Mello, 1905.

MENDES, José. Sociedade em commandita - Si, dissolvida pela expiração do prazo ajustado para a sua duração, uma sociedade em commandita, instituida entre A e B, com todas as formalidades legaes, A continua a commerciar sosinho, mas, falta verso (vire) (Memorial). São Paulo: Duprat \& Comp., 1903.

MENDES, José. A testemunha que diz a verdade em juizo, cumpre seu dever e não commette crime algum - Comarca da capital - Acção criminal (Allegações finaes). São Paulo: Duprat \& Cia., 1906. $1 \mathrm{v}$.

MENDES, José. A testemunha que diz a verdade em juizo cumpre seu dever e não commette crime algum - Comarca da capital - Acção criminal (Allegações finaes). São Paulo: Duprat \& Cia., 1906.

MENDES, José. Venda de cousa litigiosa e constituição de servidão de caminho na divisão de terras - Tribunal de Justiça de São Paulo - Appellação civel numero 4632 - Comarca de Jahu (Razões). São Paulo: Duprat \& Cia., 1906. 